\title{
Análise de situação de serviços públicos de saúde mental em Minas Gerais
}

\author{
Situation analysis of public mental health services in Minas Gerais
}

Sabrina Martins Barroso ${ }^{1}$

Avaliar os serviços de saúde mental é uma necessidade reconhecida e recomendada pela Organização Mundial de Saúde. Apesar disso, ainda constitui uma prática não sistemática no Brasil. Uma honrosa exceção é feita pela equipe envolvida nos projetos Pesquisa em Soroprevalência de Aids na Saúde Mental (Projeto Pessoas I) e na Pesquisa em Soroprevalência de Aids na Saúde Mental em Minas Gerais (Projeto Pessoas II). Sobre o último (Pessoas II) trata o livro Análise de situação de serviços públicos de saúde mental em Minas Gerais, publicado pela Editora Coopmed, no final de 2012'. O livro, organizado em cinco capítulos, aborda tanto as características dos serviços de saúde mental do estado de Minas Gerais quanto os aspectos facilitadores e dificultadores para a prevenção de doenças sexualmente transmissíveis entre a população usuária de tais serviços.

O primeiro capítulo apresenta uma atualização sobre as formas de avaliar os serviços psiquiátricos e os estudos brasileiros sobre essa temática. Apresenta, ainda, a relação existente entre transtornos mentais, comportamento sexual de risco e doenças sexualmente transmissíveis, explicando por que a população psiquiátrica é considerada população de risco para tais questões.

O segundo capítulo explica os objetivos e a parte metodológica do Projeto Pessoas II. São apresentados os objetivos, a metodologia adotada, o referencial teórico, o eixo quantitativo e qualitativo das análises e as características descritivas dos serviços investigados.

O terceiro capítulo apresenta os resultados observados a respeito do conhecimento sobre HIV/Aids, os comportamentos sexuais de risco e as formas de contágio de doenças sexualmente transmissíveis. O texto aborda também as formas de controle que os serviços de saúde mental possuem sobre tais temas, relatando a existência de investigação clínica sobre os temas no serviço, solicitação de exames, encaminhamentos, entre outros.

O quarto capítulo é destinado a comparar os resultados do estudo nacional (Projeto Pessoas I) com os resultados observados no estado de Minas Gerais, traçando um paralelo. E o quinto capítulo é destinado a analisar os facilitadores e dificultadores na prevenção das doenças sexualmente transmissíveis entre a população psiquiátrica pela ótica dos profissionais de saúde mental.

Considerando a carência de estudos abrangentes sobre os serviços de saúde mental, o risco aumentado para doenças sexualmente transmissíveis da população psiquiátrica e as informações e questionamentos trazidos na obra, o livro representa uma grande contribuição para os campos da saúde mental e da saúde pública no Brasil, sendo de interesse para a comunidade científica, para os gestores de serviços de saúde e para a população geral.

1 Universidade Federal de Minas Gerais (UFMG); Universidade Federal do Triângulo Mineiro (UFTM). 


\section{REFERÊNCIA}

1. Guimarães MDC (Org.). Análise de situação de serviços públicos de saúde mental em Minas Gerais (Projeto Pessoas II). Belo Horizonte: Coopmed; 2012. 